Randomised controlled trial

\section{Effects of an Internet-delivered cognitive behavioural therapy programme on chronic pain patients}

10.1136/ebnurs-2016-102305

\section{Dave A Bergeron}

Université du Québec à Rimouski, Quebec, Canada

Correspondence to: Dave A Bergeron, Université du Québec à Rimouski, Department of Nursing, 300, allée des Ursulines, Rimouski, Québec, Canada G5L 3A1; Dave_Bergeron@uqar.ca

Commentary on: Dear BF, Gandy M, Karin E, et al. The Pain Course: a randomised controlled trial examining an internetdelivered pain management program when provided with different levels of clinician support. Pain 2015;156:1920-1935.

\section{Implications for practice and research}

- Internet-delivered chronic pain (CP) management programmes are effective when integrated into existing health services.

- Identification and validation of essential components of an Internet-delivered $\mathrm{CP}$ management programme, as well as characteristics of patients most likely (or not likely) to benefit from such a programme, should be the participants of future research.

\section{Context}

Many studies indicate benefits of biopsychosocial CP management programmes, including cognitive behavioural therapy (CBT). Patients cannot always access such programmes, however, and consequently are undertreated. ${ }^{1}$ Internet-delivered programmes built on the same principles, but with different levels of clinician support, could be an innovative approach that promotes access to $\mathrm{CP}$ management programmes while decreasing clinicians' commitments.

\section{Methods}

This randomised controlled trial by Dear and colleagues investigated the effects on disability, depression, anxiety and pain in CP patients, of an Internet-delivered programme accompanied by one of three levels of clinician support. This eight-week programme is based on CBT principles and consists of five online sessions with five corresponding sets of skills to practise, and regular automated electronic reminders and messages of encouragement.

The initial sample was a heterogeneous group of 490 participants with CP related to a variety of conditions. They were randomised into four groups, three of which experienced the internet intervention (regular contact with clinicians, optional contact, no contact), and the wait list control group that accessed the internet intervention following the study. The outcomes disability, depression, anxiety and average pain were measured online using validated tools at recruitment, pretreatment, posttreatment and at 3-month follow-up. Researchers were blinded to randomised group allocation during recruitment and acceptance into the trial, but further blinding is not possible with these interventions. Several statistical analyses were performed including generalised estimating equations to examine changes over time.

\section{Findings}

There were significant improvements in disability, anxiety, depression and pain, both immediately post-treatment and at 3-month follow-up, with an average reduction for the outcomes of at least 18, 32, 36 and 12\%, respectively. Furthermore, no marked difference was reported between experimental groups. Participants were generally very satisfied with their participation, and for all three groups, there was a significant decrease in prescription medication and health service use between pretreatment and 3-month follow-up. Time spent by clinicians was significantly greater for the regular contact group, which required more time than the other experimental groups.

\section{Commentary}

This study demonstrates beneficial effects of an Internet-delivered programme among heterogeneous participants with various $\mathrm{CP}$ conditions. Positive outcomes are reported for every level of clinician support, even with little or no support. The research is well reported, using the CONSORT 2010 checklist. $^{2}$ Except for prescription medication use, healthcare services use, vocational status, acceptability and satisfaction, which were self-reported, other outcomes were measured with validated and reliable instruments.

Limitations include follow-up of only 3 months, so we await further reports of whether the programme effects are maintained over the longer term. Also, participants sought to take part in this type of programme and treatment options were not restricted during the trial. Those elements may have had a positive influence on the reported outcomes. CBT may be also of limited use, and has potential to cause harm, in some patients. This would dilute effectiveness, and might be considered in analyses, or maybe even for exclusion criteria, in future research.

Most CP management occurs in primary care, where a multidisciplinary or interdisciplinary approach is recommended. ${ }^{3}$ In collaboration with other health professionals, primary care nurses can play a key role in $\mathrm{CP}$ management and could be more involved in psychological approaches related to $\mathrm{CP}$, including $\mathrm{CBT}^{4}$ Further research on a primary care multidisciplinary or interdisciplinary Internet-delivered CP management programme where nurses could provide support is merited.

Other means of consultation rather than phone or face-to-face, such as text messaging and email, could be used to provide clinician support for participants in Internet-delivered CP management programmes. Electronic communications should be considered in future research, with inclusion of qualitative design elements to help understand how participants interact, in accessing clinician support. ${ }^{5}$

Competing interests None declared.

Provenance and peer review Not commissioned; internally peer reviewed.
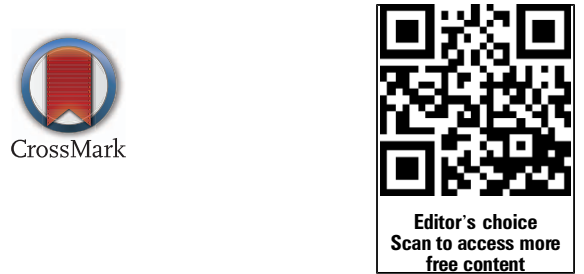

\section{References} free content

1. Gatchel RJ, McGeary DD, McGeary CA, et al. Interdisciplinary chronic pain management: past, present, and future. Am Psychol 2014;69:119-30.

2. Moher D, Hopewell S, Schulz KF, et al. CONSORT 2010 explanation and elaboration: updated guidelines for reporting parallel group randomized trials. J Clin Epidemiol 2010;63:e1-37.

3. Smith BH, Torrance N. Management of chronic pain in primary care. Curr Opin Support Palliat Care 2011;5:137-42.

4. Richardson C, Adams N, Poole H. Psychological approaches for the nursing management of chronic pain: part 2. J Clin Nurs 2006;15:1196-202.

5. Greenhalgh T, Vijayaraghavan S, Wherton J, et al. Virtual online consultations: advantages and limitations (VOCAL) study. BMJ Open 2016;6:e009388. 